\title{
Prevalence of Paediatric HIV Infection in Eastern India-First report
}

\section{Pradipta Guha ${ }^{1 *}$ and Partha Sardar ${ }^{2}$}

${ }^{1}$ Calcutta National Medical College, Kolkata, 24, Gorachand Road, Kolkata - 700014, West Bengal, India

${ }^{2}$ Department of General Medicine, Lal Bahadur Shastri Hospital, Khichripur, New Delhi-110091, India

\begin{abstract}
Prevalence of pediatric HIV has not been well characterized. We evaluate the prevalence, risks and contributing factors to the spread of HIV in India. This manuscript aims to describe prevalence of Pediatric HIV infection in Eastern India. We want to provide data on burden of HIV positive children visiting a tertiary care center located in the city of Kolkata, East India. Data is provided for routes of HIV exposure and occupational background and HIV status
\end{abstract} of the parents of infected children.

Background: Various studies in India have documented high prevalence of HIV infection in children. Nearly 20 million babies are born each year and the number of infected babies could be $>50,000$ per year. According to Solomon $\mathrm{S}$ et al in India the prevalence of HIV among pregnant women varies widely from state to state and figures range from $0.5 \%$ to as high as $4.7 \%$ as in Namakkal, a small village in Tamilnadu.

Objective: To determine and characterize the prevalence of pediatric HIVIAIDS in India

Methods: This is a two year retrospective review of patients from the (with 100 beds) pediatric outpatient unit of the Medical college and Hospital, Kokata, was undertaken to determine the prevalence of pediatric HIVIAIDS in Kokata (or in North India).

Results: 3,669 pediatric patients were admitted to the hospital, 437(11.9\%) tested positive for HIV, 234 were males, while 203 were females (m:f=1.15:1). Children under the age of five years accounted for $81.7 \%$ of the HIV positive children. Mother-to-child transmission occurred in $73.7 \%$ of cases was the major route of transmission of HIV. Two other common routes included the use of blood/blood products (21 patients), hairdressing implements due to punctures in $4.8 \%$ each, while sexual abuse/sex activities were the probable route in $3.8 \%$ others. Most mothers of HIV children were either housewives $(45.3 \%)$, or petty traders, trade that is conducted on a small scale $(10.4 \%)$.

Conclusion: The prevalence of pediatric HIVIAIDS was high in Eastern india. The most common mode of transmission was mother to child. Programs to work on education of prevention of this mode of transmission should be implemented by proper detection of disease in mothers, adequate counselling and administration of HAART to prevent mother to child transmission of AIDS.

Keywords: Prevalence; Paediatric HIV/AIDS; Paediatric outpatient unit

\section{Introduction}

HIV/AIDS remains the greatest public health crises in the world today. The estimated number of children under the age of 15 years living with this virus globally is 2.3 million [1,2] as of 2005. Asia and Africa continue to carry the greatest burden of this disease with over 1.9 million (82.6\%) children infected with HIV [1,2]. The global pandemic which has caused more than 13 million children globally to be orphaned, 11 million of which can be found in Sub Saharan Africa $[2,3]$.

HIV infection in the age group of 15-30 years is responsible for over $65 \%$ of all new cases disease in India [3]. The infection rate among young women out numbers that of their male counterparts with a ratio of 2:1 [3,4]. This trend is disturbing to pediatric care givers as over $90 \%$ of pediatric HIV/AIDS occurs via mother-to-child transmission (MTCT). Hence, the United Nations General Assembly mandate of reducing MTCT by $20 \%$ by 2005 , and $50 \%$ by 2010 has been emphasized [1] but these goals have yet to be reached in Asia and Africa.

Today, HIV/AIDS is the fourth leading cause of mortality in the world, and it is responsible for more than $7.7 \%$ of mortality in children less than five and caused a 19\% rise in infant mortality [5]. In some parts of India, the disease has surpassed malaria as the leading cause of death [6], yet for most part, pediatric HIV infection is potentially preventable through education and providing resources to reduce transmission. In industrialized nations, HIV in children is now largely under control. The reverse is the case is most developing nations due to lack of access to currently available and practical risk reduction measures. Other barriers include high maternal HIV infection rates, birth rate, heterosexual HIV transmission, female to male ratio as well as the widespread practice of prolonged breast feeding irrespective of HIV status [5,7] All these issues translate to a high burden of pediatric HIV/AIDS in India $[5,7,8]$. The sero-prevalence of HIV among pregnant women in the country increased from $1.8 \%$ in 1991 to $5.5 \%$ in 2001 , down to $4.4 \%$ by 2005 and $5.8 \%$ by 2007 with a slight drop recently [7,9]. The overall trend, is an increase rate of HIV positive mothers giving birth.

Kolkata, is considered the 'seat of power' in India, and is one of the

*Corresponding author: Pradipta Guha, RMO Cum Clinical Tutor, Departmen of General Medicine, Calcutta National Medical College, Kolkata, 335, Nandan Nagar, Belgharia, Kolkata 700083, West Bengal, India, Tel: 091-33-25412415; 091 9433126469; Fax: 091-33-22198727; E-mail: dr.pradipta@yahoo.co.in

Received July 17, 2011; Accepted September 03, 2011; Published Septembe 25, 2011

Citation: Guha P, Sardar P (2011) Prevalence of Paediatric HIV Infection in Eastern India-First report. J AIDS Clinic Res 2:127. doi:10.4172/2155-6113.1000127

Copyright: (C) 2011 Guha P, et al. This is an open-access article distributed under the terms of the Creative Commons Attribution License, which permits unrestricted use, distribution, and reproduction in any medium, provided the original author and source are credited. 
fastest growing cities in the country with a large influx of young people from different parts of the country seeking job opportunities. Since the study by Oniyangi et al in 2006, [10] on the pattern of pediatric HIV/AIDS, no similar study had been conducted. This communication documents an update on the recent prevalence of this disease in children in Kolkata. The data generated from study is expected to be of practical importance for comparative as well as prioritizing intervention measures for children at risk of the disease in the area.

\section{Subjects and Methods}

This study was carried out at the Medical College and Hospital Kolkata after the establishment of the Plan for AIDS Relief Program or (POPU) in the hospital. It is a special program sponsored by the government of the India; which provides free medical services to patients with HIV/AIDS since 2002. The hospital is one of the first of six centers in the country to benefit from such program. It is a tertiary care health institution serving many neighboring states including Bihar, Jharkhand and Orrissa. Since this study was performed at a tertiary care as well as a referral center which is located in a large city of India, it is likely to serve a mixed population (urban, suburban and migratory) of patients.However, we did not emphasise on demographic data on living conditions in this study. Children with HIV/AIDS also benefit from the program, and are seen in the pediatric outpatient specialist treatment clinic (POSTC).

This is a retrospective chart review study in which we retrieved case records of 3,669 children visiting out patients' clinic of this tertiary care facility. All the patient were screened for HIV. Of the all 437 positive patients all were reviewed in pediatric outpatient specialist treatment clinics. Appropriate informed consent was taken before inclusion of each patient. We used the World Health Organization (WHO) case classification criteria for defining "HIV positive" and "HIV exposed" children. Case records of all children less than 15 years old (age of the child at study evaluation) seen from January 2005 to December 2006 in POPU were reviewed, and those of all HIV positive children seen in POSTC were retrieved and relevant information collected. This included demographics such as age, sex, occupation of the parents, the possible mode of HIV transmission to the child, as well as the HIV status of the parents. This was the inclusion criteria or case selection criteria. Excluded from the study were children attending follow up at the POPU and HIV exposed infants who tested negative using deoxyribonucleic acid polymerase chain reaction (DNA PCR) test. Diagnosis of HIV infection in children less than 18 months was confirmed with a DNA PCR test after 6 weeks of age. For older children, the diagnosis was confirmed using a double rapid antibody test (STAT PAK by chembio diagnostic system INC New York, and Determine by Abbot Laboratories Japan). This study discloses sensitivity of $99.6 \%$ and specificity of $98.3 \%$ for enzyme immunoassay and Sensitivity was observed to be $93 \%$ of DNA PCR test and specificity was $94.5 \%$.

Data analysis was computed using SPSS program version 13.5 that produced frequency distributions, percentages, mean and standard deviations.

\section{Results}

A total of 3,669 pediatric patients were seen in POPU during the two-year review study period. All the patients were screened for HIV positivity. Four hundred and thirty seven (11.9\%) of these, comprising 234 males and 203 females ( $\mathrm{m}: \mathrm{f}=1.15: 1$ ), tested positive for HIV infection. Among them only 33 patients were previously diagnosed and included in the study.
Table 1 shows the age distribution of the children with HIV infection. Most (81.7\%) were below five years old or younger, with $29.5 \%$ less than one year old. Pediatric patients ages 5-10 had the lowest rate of HIV infection at $6.4 \%$.

The most common routes of HIV infection are shown in table 2. MTCT is the most frequent mode of transmission and was documented in $73.7 \%$ of patients. Probable transmission through blood transfusion, and use of non-disinfected hairdressing implements such as clippers, shaving blades and scissors was also recorded in $4.8 \%$ each, while in $3.9 \%$ of cases, transmission was most probable due to use of nonsterile/reused needles. Sexual abuse/activities constituted the mode in $3.4 \%$, while the source was unidentified in $6.4 \%$. Non-MTCT routes of HIV exposure via unsterilized scissors usage and tattooing was found to be higher in older age categories.

Table 2 shows the occupation of parents of HIV positive children. Seven fathers and four mothers had incomplete records and were excluded from analysis. Three pairs of twins were positive during the two years review period, while four of the mothers were single mothers, though it does not carry much significance. Three hundred and sixteen (73.5\%) of 430 mothers of HIV positive children were themselves positive for HIV infection, 101 (23.5\%) tested negative for HIV, while $13(3.0 \%)$ were not tested, including six mothers who refused to be tested. On the other hand, 132 (30.9\%) of 427 fathers of HIV positive children tested positive for HIV themselves, 46 (10.8\%) were HIV negative, and 249 (58.3\%) including 72 who refused to be tested were not available for testing. Of the 427 fathers of HIV positive children, only 178 (41.7\%) agreed to be tested, 249 (58.35) were not tested, and $179(71.1 \%)$ of fathers not available for testing and mentioned their busy schedule as their main reason for not being tested. Thus, a greater proportion of mothers (417/430 or $97.0 \%)$ than fathers $(178 / 427$ or 41.7\%) of HIV positive children agreed to be tested for HIV infection, $\mathrm{p}<0.05$.

Table 3 shows that 143 (45.3\%) of the 316 mothers of HIV positive children who were positive for HIV infection were housewives, 38 $(12.0 \%)$ were self employed, $46(14.6 \%)$ were traders including 33 (10.4\%) who were petty traders having comparatively low economic status, $32(10.1 \%)$ were civil servants, while 31 (9.8\%) were students. The occupation in which the parents were least likely to have HIV positive children include farming, being practiced by $1.5 \%$ of the fathers, and $0.9 \%$ of the mothers. Thirty five $(26.5 \%)$ of $132 \mathrm{HIV}$ positive fathers were civil servants, 26 (19.7\%) were long distant drivers, 9 (6.8\%) were short distance drivers, 24 (18.2\%) were self employed, while 19 (14.4\%) were workers in private establishments. This table compares occupation of all parents of HIV positive children with positive parents of positive children; a significant difference is noted for HIV positive fathers of positive children engaged in long distance driving as compared to all fathers of positive children. Additionally, a negative association is noted for any of the parent engaged in farming.

\begin{tabular}{|c|c|c|}
\hline Age (Years) & No of Cases & Percentage of Total \\
\hline $0-<1$ & 129 & 29.5 \\
\hline $1-<3$ & 145 & 33.2 \\
\hline $3-<5$ & 83 & 19.0 \\
\hline $5-10$ & 28 & 6.4 \\
\hline $10-15$ & 52 & 11.9 \\
\hline Total & 437 & 100 \\
\hline
\end{tabular}

Table 1: Age Distribution of the Children with HIV Infection. Age stratification was made randomly. 


\begin{tabular}{|l|l|l|l|l|l|l|l|l|}
\hline \multicolumn{1}{|c|}{ Age( Years) } & $\begin{array}{c}\text { Through MTCT } \\
(\%)\end{array}$ & $\begin{array}{c}\text { Through Blood } \\
\text { Transfusion (\%) }\end{array}$ & $\begin{array}{c}\text { Through tattooing } \\
\text { and ear piercing } \\
(\%)\end{array}$ & $\begin{array}{l}\text { Sexual abuse or } \\
\text { sex related (\%) }\end{array}$ & $\begin{array}{l}\text { Through Barbing } \\
(\text { sharp hooks ) } \\
(\%)\end{array}$ & $\begin{array}{c}\text { Through non } \\
\text { sterile needle (\%) }\end{array}$ & $\begin{array}{c}\text { Unidentified } \\
\text { source (\%) }\end{array}$ & \multicolumn{1}{|c|}{ Total } \\
\hline $0-<1$ & $121(37.6)$ & $1(4.8)$ & $0(0.0)$ & $0(0.0)$ & $2(9.5)$ & $0(0.0)$ & $5(17.9)$ & $129(29.5)$ \\
\hline $1-<3$ & $124(38.5)$ & $6(28.6)$ & $1(7.7)$ & $0(0.0)$ & $6(28.6)$ & $2(11.8)$ & $6(21.4)$ & $145(33.2)$ \\
\hline $3-<5$ & $67(20.8)$ & $8(38.1)$ & $2(15.4)$ & $0(0.0)$ & $2(9.5)$ & $3(17.6)$ & $1(3.6)$ & $83(19.0)$ \\
\hline $5-15$ & $10(3.1)$ & $6(28.6)$ & $10(76.9)$ & $15(100)$ & $11(52.4)$ & $12(70.6)$ & $16(57.1)$ & $80(18.3)$ \\
\hline Total & $322(73.7 \%)$ & $21(4.8 \%)$ & $13(3.0 \%)$ & $15(3.4 \%)$ & $21(4.8 \%)$ & $17(3.9 \%)$ & $28(6.4 \%)$ & $437(100 \%)$ \\
\hline
\end{tabular}

Table 2: Probable Source of Pediatric HIV Infection.

\begin{tabular}{|c|c|c|c|c|}
\hline \multirow[b]{2}{*}{ Occupation } & \multicolumn{2}{|r|}{ Mothers } & \multicolumn{2}{|c|}{ Fathers } \\
\hline & $\begin{array}{l}\text { No }(\%) \\
\text { With +ve Children } \\
N=430\end{array}$ & $\begin{array}{l}\text { No }(\%) \\
\text { +ve For HIV } \\
N=316\end{array}$ & $\begin{array}{l}\text { No }(\%) \\
\text { With +ve Children } \\
N=427\end{array}$ & $\begin{array}{l}\text { No }(\%) \\
+ \text { Ve For HIV } \\
\mathrm{N}=132\end{array}$ \\
\hline Unemployed & - & - & $12(2.8)$ & $3(2.3)$ \\
\hline Housewife & $192(44.7)$ & $143(45.3)$ & - & - \\
\hline Self-employed & $49(11.4)$ & $38(12.0)$ & $97(22.7)$ & $24(18.2)$ \\
\hline Private employed & $25(5.8)$ & $20(6.3)$ & $48(11.2)$ & $19(14.4)$ \\
\hline Civil servant & $54(12.6)$ & $35(11.1)$ & $101(23.7)$ & $35(26.5)$ \\
\hline Trading & $53(12.3)$ & $46(14.6)$ & $51(11.9)$ & $9(6.8)$ \\
\hline Long Distance Drivers & - & - & $49(11.5)$ & $26(19.7)$ \\
\hline \multicolumn{5}{|l|}{ Short Distance Drivers } \\
\hline Farmers & - & - & $26(6.1)$ & $9(6.8)$ \\
\hline \multirow{2}{*}{ Students } & $17(4.0)$ & $3(0.9)$ & $28(6.6)$ & $2(1.5)$ \\
\hline & $40(9.3)$ & $31(9.8)$ & $15(3.5)$ & $5(3.9)$ \\
\hline TOTAL & $430(100)$ & $316(100)$ & $427(100)$ & $132(100)$ \\
\hline
\end{tabular}

Table 3: Occupation of Parents of HIV Positive Children.

\section{Discussion}

The present data indicates that the increasing trend is unabated in India and AIDS in children is emerging as a serious problem. The explosive global epidemic has disproportionately affected the developing world notably Africa and South East Asia including India. The high prevalence of pediatric HIV/AIDS (11.9\%) from this study indicates that HIV is a major problem in India. We compared our study result with African data that has been previously characterized. In reality, despite this high prevalence, there is an underestimation of the scope of the problem considering that many of these children with HIV/AIDS might have died without reaching a health facility and the diagnosis might have been missed. The prevalence rate of $11.9 \%$ was higher than the 5.7\% earlier reported by Oniyangi et al. [10], and much higher than $1.5 \%$ reported by Angyo et al. [11]. It is however similar to the $13.7 \%$ reported by Ojukwu et al. [12] from Abakiliki. Karande et al. have reported a seroprevalence of $11.2 \%$ among hospitalized children in 2002 in Mumbai [13]. Parthasarathy et al. reported a prevalence of 8.9\% in 2006 in New Delhi [14]. The differences in the prevalence rate may lie in the nature of the city of Kolkata, and the free HIV medical services offered in our institution. Kolkata is one of the fastest growing cities in the country which has experienced an influx of young people seeking employment in the city. A beginning has been made in this direction in the Union Territory. The situation in Punjab, however, is much more serious as evident from the HIV positivity rates in adults [15]. The increase in HIV cases is unabated in the northern region also in spite of massive IEC programme launched by NACO. HIV infection is predominantly a disease of sexually active young individuals who have the highest burden of this disease [7,9] and can transmit the virus to their children. Although NACO has listed prevention of mother to child transmission a priority area and the international response to the HIV/AIDS epidemic has been outstanding [16]. The high influx of young people into the city and the free medical HIV services at the institution might encourage people to be tested for HIV knowing they could receive treatment and encourage HIV positive individuals to come and seek care.

The age distribution of the children in this study does not differ much from other studies conducted in Sub Saharan Africa [11,12,1719], and elsewhere in Africa [20,21]. According to reports from other studies [5,21], over half of these children manifest the features of the disease by the age of three years. In the present study, $30 \%$ of HIV/ AIDS children were less than one year, and $81.7 \%$ were under five years. Tindyewa et al. [5], also noted that $25-30 \%$ of the perinatally acquired HIV infection in children will manifest or succumb to the disease before their first birthday. All these reflect the magnitude and influence of maternal HIV infection in their children, and a shorter incubation period of this infection in children when compared to adults due to alteration in maternal immunity.

Although MTCT of HIV infection has been identified as the most common route exposure in children, accounting for over $85 \%$ of pediatric HIV/AIDS, $(5,6,9,18)$, there seems to be a variation in rates by demographics in MTCT route of HIV infection in India. For example, MTCT was responsible for $73.7 \%$ of HIV infection in the present study, a situation similar to $67.7 \%$ from Abakiliki [12] and $69.6 \%$ from Jos [11], but differs significantly from the reported $30.0 \%$ from Enugu [18]. The study from Enugu was undertaken when HIV screening of donor blood was not widely available. In addition to the difference in the study periods, that it was conducted near about 16 years back the present study used age appropriate HIV DNA PCR test for diagnosis of HIV in young children, though the technique remains the same for all age groups. Another Indian study by Sehgal $S$ et al disclosed Perinatal transmission accounting for nearly $90 \%$ of infections in the neonates [22]. There is now a substantial help from Bill and Melinda Gates foundation to combat AIDS in India, which needs to be used judiciously. If we cannot treat effectively the mothers with internationally accepted regimens one can still reduce the burden of new infections in the babies. 
In India, most initial reports in pediatric HIV infection were focused on multi-transfused recipients such as thalassemics [23]. With mandatory screening of blood products, the incidence of transfusionassociated HIV infection has reduced dramatically and is now seen only sporadically. In spite of this decrease, pediatric HIV infection has become an important public health issue due to a sharp rise in infection rates among women. This is particularly true for India where the major mode of transmission is heterosexual contact [14]. The World Health Organization (WHO) estimated that up to $10 \%$ of AIDS cases in India result from transfusion of infected blood. The present study estimated transmission through infected blood occurred in $4.8 \%$ of HIV positive cases. This was much less than figures from other areas in the world, such as $30.0 \%$ in Enugu [18], 12.9\% in Abakiliki [12] and 8.9\% in Jos [11]. It was however, similar to the $4.6 \%$ earlier reported from Abuja by [10], though this variation is quite acceptable and does not carry any significance. The lower transmission rate of HIV infection by blood transfusion recorded in this study could be attributed to the blood screening process present at Hospital Kolkota. This technique utilized in "Safe Blood for Africa" in our health institution uses all inclusive testing algorithms which detects both antibodies and HIV viral DNA in the donors' blood before transfusion [24].

Use of unsterile needles for intramuscular injections is a common practice among the patient medicine dispensaries across the country. This is particularly prevalent in rural, semi-rural, and urban slums where majority of the populace resides and patronizes these informal health care providers for their health needs. In this study, 3.9\% of the children were suspected to have contracted HIV via this route of transmission.

Sexual abuse is another risk factor and highly prevalent although often unreported Girls may be sexually abused by men who are infected with HIV [17]. It is estimated that sexual abuse was responsible for $3.4 \%$ of HIV infection in pediatric patients in the present study. The transmission rate was unknown in $6.4 \%$ of cases in the present study.

It is interesting to note that $45.3 \%$ of mothers of HIV positive children in this study were considered "house wives". This is compared to Angyo et al. [11] who reported $60.9 \%$ of housewives being mothers of HIV positive children in their study suggesting decreased family income due to a single working parent might contribute to a higher incidence of HIV infection. As noted by studies from African countries $[25,26]$, HIV/AIDS is a disease of poverty that affects predominantly farmers and women. The findings from this report that farmers were the least affected parents of HIV positive children differ significantly from results obtained from other areas $[25,26]$ and may also suggest that HIV may be more prevalent in urban rather than rural areas. For the fathers of HIV positive children, HIV infection was more prevalent among civil servants and long distance drivers. This group of workers have a tendency to patronize commercial sex workers who are reported to have a high incidence of HIV (35-75\% of cases) [27,28].

More aggressive measures are required to reduce the spread of HIV among long distance drivers especially through education and the promotion of condom usage. The high prevalence among civil servants in this study also points to the fact that this group of workers may be at risk. The study also shows that $23.5 \%$ of mothers of HIV positive children were negative for HIV infection, and emphasizes the possibility of other modes of transmission of HIV in children apart from MTCT. This requires further studies to dig out the exact underlying cause. Interventions aimed at reducing HIV infection in children should also address other means of acquiring this disease.

Our study have many limitations like barriers to testing, possible other causes for transmission of HIV etc, which will be revealed in near future.

\section{Conclusion}

The prevalence of HIV/AIDS in children is high in the Eastern India most of which was through occurs through mother-to-child transmission. There is an urgent need to scale up PMTCT of HIV programs to many tertiary, secondary and primary health care facilities across the nation. In view of the high and increasing burden of HIV infection in the study population, there is also an urgent need for a consorted effort by government, public, non-government agencies and individuals to propagate and establish preventive measures against this disturbing trends. Issues regarding lack of education, need for sterile needle distribution and disposal, screening of blood products and most importantly, education to work to prevent mother-child transmission need to be addressed. Some possible solutions might include: Safe blood for African initiative/ techniques should be extended to health care facilities nationwide. The use of unsterile needles by patient medicine dealers must be prohibited.

Future research should aim at finding out the limitations like barriers to testing and possible other causes for transmission of HIV.

\section{References}

1. UNAIDS/WHO. Global summary of the HIV and AIDS Epidemic. December 2005. http:// unaids.org/EN/resources/epidermiology/epicore:asp

2. UNAIDS 2004 Report on the global AIDS epidemic, $4^{\text {th }}$ global report, 2004.10 (UNAIDS/04.16E). Geneva

3. Gregson S, Garret GP, Aderson RM (1994) Is HIV likely to become aleading cause of adult mortality in sub-Saharan Africa. J Acquir Immune Defic Syndr 7: 839-852.

4. Carovano K (1997) Women and AIDS: The challenges and the responses of UNAIDS: Women and AIDS in Africa Scientific Symposium Report, Abidjan. African AIDS Research Network, May: 39-43.

5. Tindyebwa D, Kayita J, Musoke P, Eley B, Nduati R (2005) In Handbook of AIDS in Africa by the African Network for the care of children affected by AIDS, $2^{\text {nd }}$ Eds; 33-50

6. Scheibar GB, Bush MP, Klanmian SH, Korelitz JJ (1996) The risk of Transfusion transmitted viral infection. N Eng J Med 34: 85-90.

7. Federal Ministry of Health (2007) National guideline for paediatric HIV and AIDS.

8. Karim PM (2000) Paediatric issues in HIV infection in the developing countries Postgraduate Doctor 24: 51-56

9. Federal Ministry of Health (2007a) National Guidelines on prevention of Motherto- child transmission of HIV (PMTCT)

10. Oniyangi O, Awani B, Iregbu KC (2006) The pattern of Paediatric HIVIAIDS as seen at the National Hospital Abuja Nigeria. Nig Clin Pract 9: 157-162.

11. Angyo OIA, Okpeh ES, Onah J (1998) AIDS in Jos Nigeria. WAJM 17: 268-272.

12. Ojukwu JU, Ogbu CN (2007) HIV infection in hospitalized children with endemic diseases in Abakiliki, Nigeria: the role of clinical directed selective screening in diagnosis. AIDS Care 19: 330-336.

13. Karande S, Bhalke S, Kelkar A, Ahuja S, Kulkarni M, et al. (2002) Utility of clinically directed selective screening to diagnose HIV infection in hospitalized children in Bombay, India. J Trop Pediatr 48: 149-155.

14. Parthasarathy P, Mittal SK, Sharma VK, (2006) Prevalence of Paediatric HIV in New Delhi. Indian J Pediatr 73: 205-207.

15. Sehgal S (1998) HIV epidemic in Punjab, India: time trends over a decade. Bull World Health Organ 76: 509-513. 
Citation: Guha P, Sardar P (2011) Prevalence of Paediatric HIV Infection in Eastern India-First report. J AIDS Clinic Res 2:127. doi:10.4172/21556113.1000127

16. Piot P, Coll Seck AM (2001) International Response to HIVIAIDS Epidemic: planning for success. Bull World Health Organ 79: 1093-1186

17. Asindi A (1991) A On overview of HIVIAIDS in Africa. Nig J Paediatr 51-56.

18. Emodi IJ, Okafor GO (1995) Clinical Manifestation of HIV Infection in Children in Enugu, Nigeria. J Trop Paediatr 44: 73-76.

19. Adejuyigbe EA, Oyelami O, Onayemi O, Durosinmi MA (2003) HIVIAID in IleIfe, Nigeria. Cent Afr J Med 49: 74-78.

20. Chintu C, Luo C, Bhat G, Dupont HL, Mwansa-Salama P, et al. (1995) Impact of the Human Immunodeficiency Virus type-1 on common illness in Zambia. J. Trop Paediatr 41: 348-353.

21. Verter KM, Djomand G, Zadi F, Diaby I Bratteggard K, Timite M, et al. (1996) Clinical Spectrum of Human Immunodeficiency Virus Disease in Children in a West African City. Infect Dis 15: 438-442.

22. Sehgal S, Datta U, Arora S, Singh S (2008) Time Trends of Paediatric HIV Infection in North India. Journal of Indian Medical association 160: 162-164.
23. Sen S, Mishra NM, Giri T, Pande I, Khare SD, et al. (1993) Acquired immunodeficiency syndrome (AIDS) in multitransfused children with thalassemia. Indian Pediatr 30: 455-460.

24. Constantine NT, Saville RD, Dax EM (2005) Enzymes immunoassays. In Retroviral testing and quality assurance: Essentials for laboratory diagnosis. MedMira Laboratory, Inc, Halifax. Canada. 147-152.

25. Topouzis D (1998) The implications of HIVIAIDS for rural development policy and programming: Focusonsub-SaharanAfrica,study pape r No.6UNDP. http: // www.undp.org/h I v / publ ications/study/englis/sp6e.htm.

26. Guerny J (2000) AIDS and agriculture in Africa. Can agriculture policy make a difference?

27. Nafula J Uganda (2008) HIV cases soars among Kampala sex workers. The Monitor 9 May.

28. Paranjothy S, Weiss H, Buve A, Morison L (2002) Factors associated with HIV infection among sex workers in four cities in sub-Saharan Africa. Int Conf AIDS. July $12 ; 14$. Abstract no. MoPeC3493. 